\title{
APLIKASI TUNTUNAN IBADAH BERDASARKAN RUKUN ISLAM DENGAN MENGGUNAKAN ANDROID
}

\author{
Fatsyahrina Fitriastuti \\ Jurusan Teknik Informatika Fakultas Teknik Universitas Janabadra Yogyakarta \\ Jl. Tentara Rakyat Mataram No. 55-57 yogyakarta 55231 \\ email : fitri@janabadra.ac.id
}

\begin{abstract}
Pillars of Islam is the pillar of religion for Muslims and becoming a Muslim general guidelines in worship to God. Pillars of Islam consists of creed, prayers, practice regular charity, fasting and pilgrimage implement. To that end, it has been widely circulated in the community to practice various types of guidance began daily prayers, fasting, zakat or hajj as a guide in conducting worship properly according to Islamic law. There are various types of guidance in the form of books, CDs or often found through internet sites. But different types of worship are guidance is less practical because it is not 'mobile' , while the higher mobility of people. Android is an open operating system that is intended for smart phones that are currently in great demand by the public. This research is to design and build an application based on the guidance of worship Pillars of Islam by using the Android operating system that can run on Android-based smartphones and can learn anytime and anywhere without being limited by space and time. Worship contains guidance material in the form of text, audio and video equipped fard prayer reminder alarms.
\end{abstract}

\section{Keywords: Applications, Andoid, Guidanceworship}

Rukun Islam merupakan tiang agama bagi ummat Islam dan menjadi pedoman umum seorang muslim dalam beribadah kepada Allah. Rukun Islam terdiri dari syahadat, mendirikan shalat, menunaikan zakat, melaksanakan puasa dan menunaikan haji. Untuk itu, telah banyak beredar di masyarakat berbagai jenis tuntunan menjalankan ibadah mulai ibadah sholat, puasa, zakat atau haji sebagai panduan dalam melaksanakan ibadah dengan benar sesuai syariat Islam. Berbagai jenis tuntunan tersebut ada dalam bentuk buku, CD atau banyak dijumpai melalui situs-situs internet. Tetapi berbagai jenis tuntunan ibadah tersebut dirasa kurang praktis karena tidak bersifat 'mobile', sementara mobilitas manusia semakin tinggi. Android merupakan sistem operasi terbuka yang diperuntukkan untuk smart phone yang saat ini sedang sangat diminati oleh masyarakat. Penelitian ini merancang dan membangun suatu aplikasi tentang tuntunan ibadah berdasarkan Rukun Islam dengan menggunakan sistem operasi Android sehingga dapat berjalan pada smartphone berbasis Android dan dapat dipelajari dimana dan kapan saja tanpa dibatasi ruang dan waktu. Tuntunan ibadah berisi materi dalam bentuk teks, audio video dan dilengkapi alarm pengingat shalat fardhu.

Kata Kunci : Aplikasi, Android, Tuntunan Ibada

\section{PENDAHULUAN}

Dalam agama Islam, terdapat lima pilar yang menciri khaskan seorang muslim. Pilar ini disebut sebagai Rukun Islam. Rukun Islam inilah yang menjadi pedoman umum seorang muslim dalam beribadah kepada Allah.

Adapun Rukun Islam itu sendiri, adalah pertama, Syahadat yaitu pengakuan bahwa tidak ada Tuhan yang patut disembah, selain Allah SWT, kedua, mendirikan shalat, ketiga, menunaikan zakat, keempat, puasa pada bulan Ramadhan dan kelima, Haji ke Baitullah AlHaram.Lima hal tersebut merupakan tiang agama bagi ummat Islam dan wajib dilaksanakan oleh setiap ummat Islam. Untuk itu, telah banyak beredar di masyarakat berbagai jenis tuntunan menjalankan ibadah mulai ibadah sholat, puasa, zakat atau haji sebagai panduan atau pedoman dalam melaksanakan ibadah dengan benar sesuai syariat Islam. Berbagai jenis tuntunan tersebut ada dalam bentuk buku, $C D$ atau banyak dijumpai melalui situs-situs internet. Tetapi berbagai jenis tuntunan ibadah tersebut dirasa kurang praktis karena tidak bersifat 'mobile', sementara mobilitas manusia semakin tinggi. Dengan perkembangan teknologi 
informatika dan komunikasi yang begitu pesat pada jaman sekarang dapat dimanfaatkan untuk mendapatkan solusi yang lebih efektif dan efisien.

Aktifitas yang semakin padat, membuat manusia memiliki sedikit waktu luang. Namun disisi lain, manusia juga wajib menyisihkan waktunya untuk beribadah sebagai wujud ketakwaan kepada Sang Pencipta. Karena ibadah merupakan tiang agama. Namun karena masih ada keterbatasan pengetahuan dan minimnya waktu yang dimiliki oleh sebagian umat Muslim dikarenakan aktifitas sehari-hari, maka tuntunan-tuntunan berbagai ibadah baik shalat, puasa, zakat maupun berhaji, terkadang masih kurang dimengerti dan kurang dipahami sehingga membuat sebagian umat Islam masih banyak yang belum dapat melaksanakan ibadah dengan baik dan benar sesuai yang diperintahkan Allah SWT.

Salah satu perkembangan teknologi informasi dan komunikasi yang saat ini sedang berkembang pesat adalah ponsel dengan sistem operasi Android. Android merupakan sistem operasi terbuka yang diperuntukkan untuk mobile device dan smart phone yang saat ini sedang sangat diminati oleh masyarakat. Android merupakan salah satu sistem operasi berbasis Linux yang bersifat open source yang dapat digunakan di perangkat mobile. Tujuan utama dari sistem operasi Android adalah untuk memajukan inovasi-inovasi piranti telepon bergerak agar pengguna mampu menikmati hasil eksplorasi dari kemampuan mobile sistem operasi Android dibandingkan dengan sistem operasi mobile lainnya.

Dengan melihat uraian diatas, bahwasanya masih ada sebagian umat Muslim yang masih kurang mengerti dan memahami dalam tuntunan menjalankan ibadah berdasarkan rukun Islam sesuai dengan yang diperintahkan Allah SWT, dikarenakan aktifitas dan rutinitas umat Muslim yang begitu padat dan juga mobilitas yang semakin tinggi sehingga menyebabkan sebagian umat Muslim tidak punya waktu banyak untuk mempelajari secara khusus panduan menjalankan ibadah yang baik dan benar. Didukung dengan semakin berkembangnya teknologi informasi dan komunikasi terutama mobile device dan smart phone dengan sistem operasi Android yang bersifat open source, maka rumusan masalah yang diangkat adalah bagaimana merancang dan membangun suatu aplikasi tentang tuntunan ibadah berdasarkan Rukun Islam yaitu syahadat, sholat, puasa, zakat dan haji dengan menggunakan sistem operasi Android yang dapat dijalankan pada mobile device dan smart phone sehingga dapat dipelajari dimana dan kapan saja tanpa dibatasi ruang dan waktu. Tuntunan ibadah berisi materi dalam bentuk teks, audio video dan dilengkapi alarm pengingat shalat fardhu.

Di dalam pembuatan aplikasi ini, penulis menggunakan software Eclipse yang bersifat IDE (Integrated Development Environment) yaitu suatu aplikasi yang menyediakan fasilitas lengkap untuk seorang programmer agar dapat mengembangkan aplikasi perangkat lunaknya, sehingga diharapkan aplikasi yang akan dibuat dapat berjalan sesuai dengan apa yang diinginkan.

Tujuan yang ingin dicapai dari penelitian ini adalah merancang dan membuat Aplikasi Tuntunan Ibadah Sesuai Rukun Islam Dengan Menggunakan Android sehingga bisa digunakan oleh kalangan umat Muslim sebagai pedoman menjalankan ibadah.

\section{TINJAUAN PUSTAKA}

Beberapa studi penelitian yang telah lebih dahulu dilakukan diantaranya adalah Sistem Informasi Berbasis Multimedia Tentang Tata Cara Ibadah Sholat Menurut Sunnah Nabi Menggunakan Macromedia Flash (Saktiawan, D., 2008) yang menghasilkan suatu sistem informasi yang hanya berisikan tentang tata cara menjalankan ibadadah sholat yang dirancang dengan software Macromedia Flash yang harus dijalankan dengan menggunakan komputer sehingga tidak praktis dan efisien.

Penelitian yang telah dilakukan Pinandita, T dan Mulyono (2010), dengan judul Aplikasi Handphone Pengingat Waktu Sholat Menggunakan Java 2 Micro Edition menghasilkan aplikasi yang hanya berisi fasilitas pengingat waktu sholat tanpa ada tuntunan atau tata cara menjalankan ibadah sholat.

Sholiha, F \& Fauzi, K.M. (2009) menghasilkan penelitian yang berjudul Panduan Ibadah Haji dan Umroh Berbasis Ponsel, menyediakan aplikasi berbasis ponsel dengan tujuan untuk memudahkan calon jamaah haji di dalam menjalankan ibadah haji dan umroh sesuai dengan syariat Islam. Dengan aplikasi ini diharapkan dapat mempermudah dan mengingatkan jamaah haji dalam melakukan proses ibadah haji dan umroh.

Sementara itu Amiral, M (2010), menghasilkan penelitian yang berjudul Aplikasi Pengingat Shalat dan Arah Kiblat menggunakan Global Positioning System (GPS) berbasis Android 1.6. 
Aplikasi hanya ini berisikan tentang pengingat shalat dan arah kiblat dengan memanfaatkan global positioning sistem (GPS) pada smartphone android 1.6 tanpa ada tuntunan atau tata cara menjalankan ibadah sholat.

Dari beberapa penelitian yang telah diuraikan diatas, penulis ingin melakukan penelitian yang dapat menghasilkan aplikasi berbasis mobile dan dapat berjalan pada mobile device dan smart phone yang menggunakan sistem operasi Android. Aplikasi ini berisi materi lengkap tentang tuntunan ibadah sesuai dengan rukun Islam yaitu syahadat, sholat, puasa, zakat dan haji. Aplikasi ini dirancang dan dibangun supaya dapat digunakan secara mudah, praktis dan efisien dapat dipakai dimana saja dan kapan saja tanpa dibatasi ruang dan waktu.

\section{METODE PENELITIAN}

Metode adalah suatu cara atau teknik yang sistematik untuk mengerjakan atau menyelesaikan sesuatu.Metodologi penelitian yang digunakan untuk dalam penelitian ini yaitu :

1. StudiKepustakaan

Merupakan metode yang dilakukan dengan mengumpulkan data yang akan digunakan dalam pembuatan aplikasi ini bersifat teoritis dengan cara membaca buku-buku, makalah, jurnal dan membaca bahan-bahan sumber referensi lainnya.

2. Pengembangan Aplikasi

Metode pengembangan aplikasi yang digunakan pada penelitian ini adalah SDLC (System Development Life Cycle) yang meliputi tahap Analysis, Design, Implementation, Testing dan Maintenance, (Pressman,2002) yaitu

a. Studi Literatur

Tahap ini merupakan tahap pengumpulan informasi dan literatur yang diperlukan untuk pembuatan aplikasi. Adapun informasi dan literatur yang dipergunakan diantaranya mengenai pedoman/tuntunan menjalankan ibadah sesuai rukun Islam yaitu dua kalimat syahadat, sholat, puasa di bulan Ramadhan, membayar zakat dan berhaji, mencari informasi mengenai Android dan versi-versi Android, mengenai Eclipse, SQL Lite sebagai database dan sebagainya.

b. Analisis dan Perancangan

Pada tahap ini dilakukan analisis serta desain yang diperlukan dalam membuat sistem, diantaranya perancangan DFD, perancangan database, dan perancangan user interface.

c. Coding

Pada tahap ini, rancangan sistem yang telah dibuat akan diimplementasikan dengan melakukan coding program Eclipse dan database SQL Lite.

d. Uji coba dan evaluasi

Pada tahap ini, akan dilakukan uji coba dan evaluasi terhadap sistem serta akan dilakukan perbaikan-perbaikan yang diperlukan. Ujicoba dilakukan dengan memasang aplikasi pada server lokal.

e. Implementasi

Tahap terakhir adalah mengimplementasikan aplikasi yang telah dibuat dan telah diuji server lokal. Aplikasi akan disimpan dalam hosting dengan nama domain tertentu.

\section{HASIL DAN PEMBAHASAN}

Perancangan Sistem

Perancangan sistem merupakan gambaran pembuatan suatu sistem dengan menggunakan Unified Modeling Language (UML), yaitu sebuah bahasa yang telah menjadi standar dalam industri untuk visualisasi, merancang dan mendokumentasikan sebuah sistem perangkat lunak. Adapun berikut perancangan sistem aplikasi mobile tuntunan ibadah shalat dan alarm pengingat shalat fardhu ini :

1. Hierarchy plus Input-Proses-Output (HIPO)

HIPO (HierarchyplusInput-Proses-Output) merupakan metodologi yang dikembangkan dan didukung oleh IBM. HIPO adalah alat dokumentasi program, yang digunakan sebagai alat desain dan teknik dokumentasi dalam siklus pengembangan sistem. Berikut gambar VisualTabelofContents (VTOC) untuk aplikasi tuntunan ibadah berdasar Rukun Islam ini: 


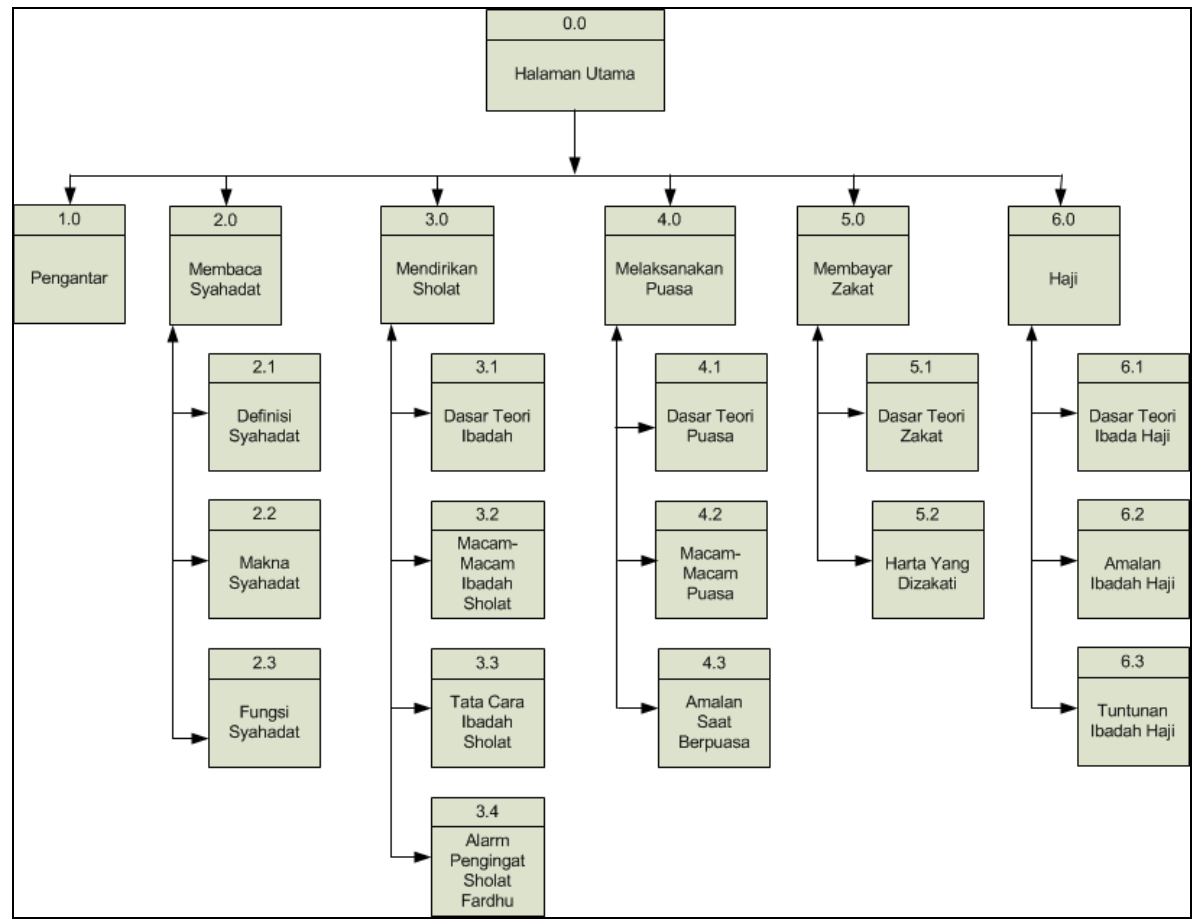

Gambar 1. Diagram Visual Table of Content

2. Use Case Diagram

Use case diagram merupakan gambaran yang diharapkan dari sebuah sistem. Sebuah use case mempresentasikan sebuah hubungan atau interaksi antara pengguna dengan sistem. Berikut usecase diagram dari aplikasi mobile tuntunan ibadah berdasarkan rukun Islam ini :

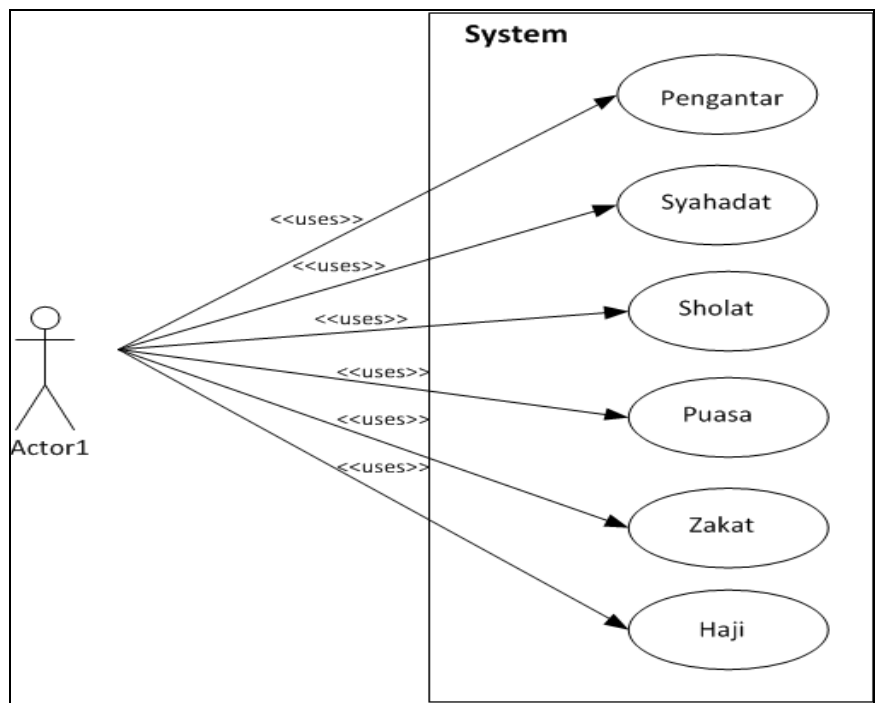

Gambar 2. Diagram Use Case

Implementasi Sistem

a. Tampilan Halaman Awal

Tampilan halaman awal sistem berisi Pengantar dari aplikasi ini. User dapat memilih tombol Lanjut untuk masuk ke halaman menu atau memilih tombol Keluar untuk keluar dari sistem. Tampilan halaman awal dapat dilihat pada Gambar 3. 


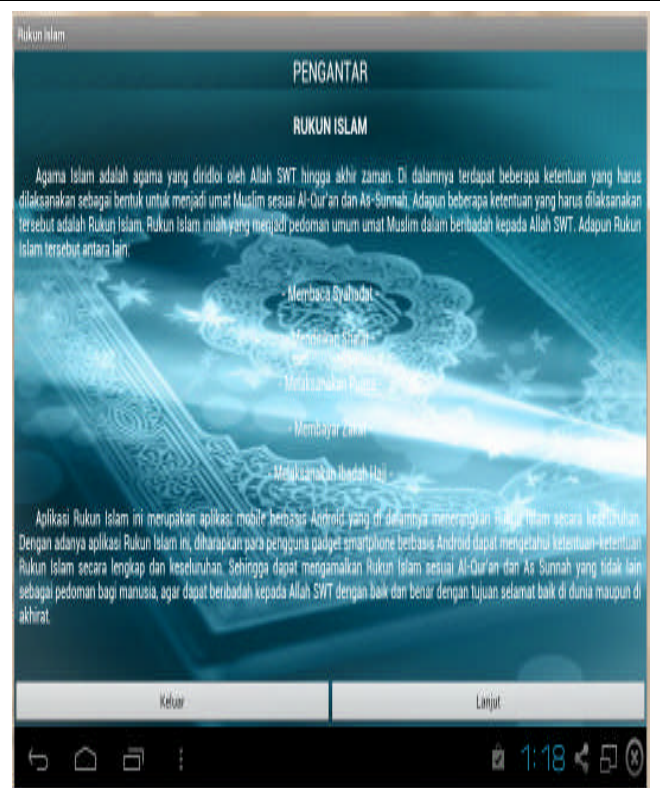

Gambar 3. Halaman Awal Sistem

b. Tampilan Halaman Menu

Jika dari halaman awal, user memilih tombol Lanjut, maka sistem akan menuju ke halaman menu seperti Gambar 4. Dari halaman ini, user dapat memilih menu yang diinginkan yaitu :

- Membaca Syahadat,

- Mendirikan Sholat,

- Melaksanakan Puasa,

- Membayar Zakat dan

- Melaksanakan Ibadah Haji.

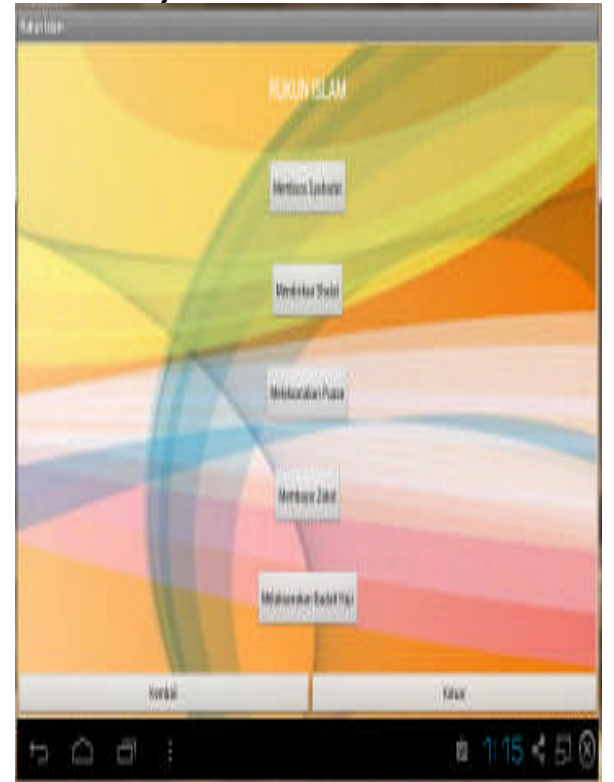

Gambar 4. Halaman Menu

c. Halaman Menu Membaca Syahadat

Halaman menu membaca syahadat, terdiri dari beberapa sub menu lagi, yaitu Definisi Syahadat, Makna Syahadat dan Fungsi Syahadat (Gambar 5). Masing-masing sub menu berisi penjelasan yang lengkap sesuai dengan judul sub menu tersebut dalam bentuk teks. 


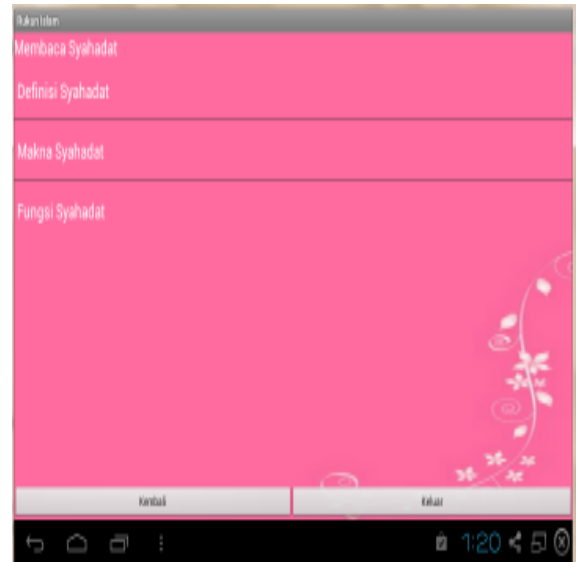

Gambar 5. Halaman Sub Menu Membaca Syahadat

d. Halaman Menu Mendirikan Sholat

Halamanmenu mendirikan sholat terdiri dari enam sub menu yaitu Dasar Teori Shalat, Macam-Macam Ibadah Sholat, Tata Cara Ibadah Sholat dan Alarm Pengingat Sholat Fardhu (Gambar 6). Masing-masing sub menu berisi penjelasan sesuai dengan judul sub menu, kecuali sub menu alarm pengingat waktu, yang merupakan fasilitas untuk memasukkan waktu sholat, sehingga pada saat tiba waktunya sholat, dapat mengingatkan user untuk sholat tepat waktu.

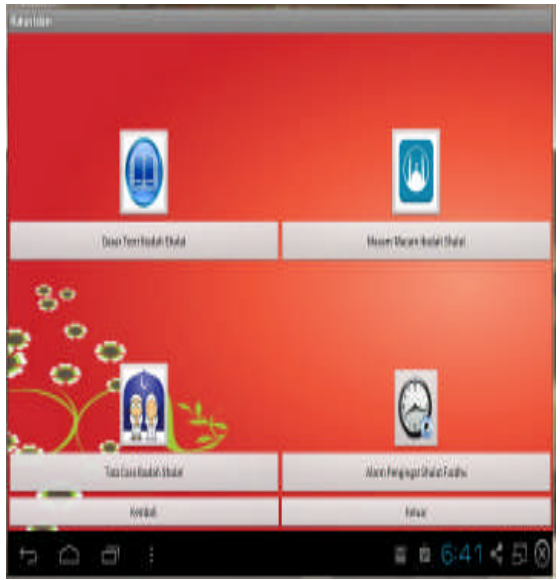

Gambar 6. Halaman Sub Menu Mendirikan Sholat

e. Halaman Menu Melaksanakan Puasa

Halaman menu melaksanakan puasa terdiri dari tiga sub menu yaitu Dasar Teori Puasa, Macam-Macam Puasa, dan Amalan Saat Puasa (Gambar 7). Masing-masing sub menu berisi penjelasan sesuai dengan judul sub menu.

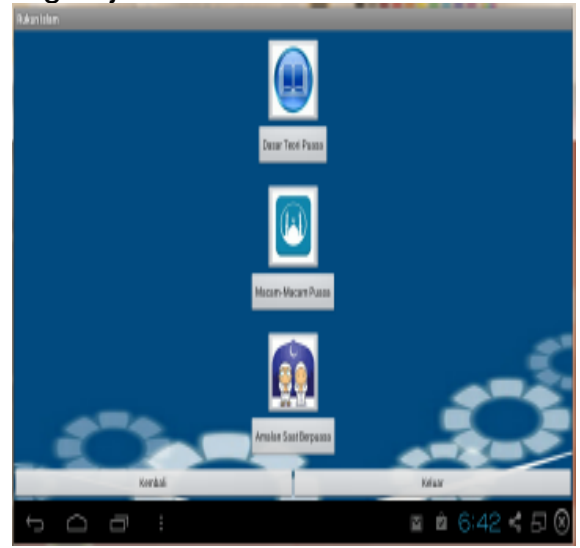

Gambar 7. Halaman Sub Menu Melaksanakan Puasa 
f. Halaman Menu Membayar Zakat

Halaman menu membayar zakat terdiri dari dua sub menu yaitu Dasar Teori Zakat dan Harta yang Dizakati (Gambar 8). Masing-masing sub menu berisi penjelasan sesuai dengan judul sub menu.

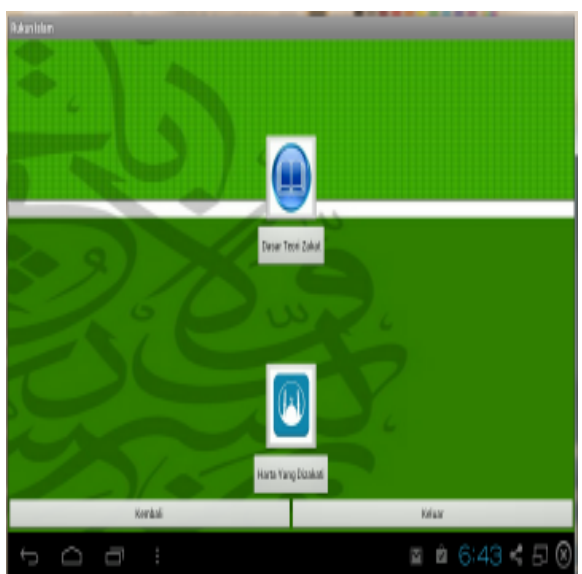

Gambar 8. Halaman Sub Menu Membayar Zakat

g. Halaman Menu Melaksanakan Ibadah Haji

Halaman menu melaksanakan ibadah haji terdiri dari tiga sub menu yaitu Dasar Teori Ibadah Haji, Amalan Ibadah Haji dan Tuntunan Ibadah Haji (Gambar 9). Masing-masing sub menu berisi penjelasan sesuai dengan judul sub menu.

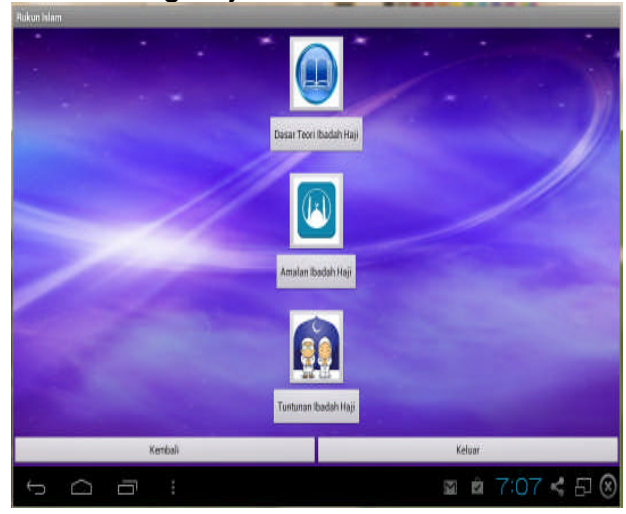

Gambar 9. Halaman Sub Menu Melaksanakan Ibadah Haji

\section{KESIMPULAN}

Kesimpulan

Dari hasil kegiatan penelitian yang telah dilakukan dapat ditarik beberapa kesimpulan, yaitu :

1. Telah dapat dirancang sebuah sistem yang menghasilkan aplikasi tuntunan ibadah sesuai rukun Islam yang berjalan diatas sistem operasi Android dengan syarat Android versi 2.2.

2. Aplikasi yang dihasilkan dibuat dengan beberapa dukungan perangkat lunak yaitu Java Development Kit (JDK) versi 6, Java Runtime Environment (JRE) versi 1.6.0_16, Android Software Development Kit (SDK) versi 1.8, sebagai alat bantu dan API dalam mengembangkan aplikasi berbasis Android dengan menggunakan bahasa pemrograman Java danEclipse versi Indigo, sebagai tools pengembangan aplikasi berbasis Java atau Android serta Android Development Tools (ADT) versi 17, sebagai plugins penghubung antara Eclipse dan Android SDK agar mempermudah dalam coding aplikasi Android.

3. Setelah dilakukan uji coba, aplikasi ini dapat berjalan baik pada sistem operasi Android mulai versi 2.2 ke atas dan dapat ditampilkan dengan baik pula di berbagai ukuran layar smartphone.

Saran

Pembuatan Aplikasi Tuntunan Ibadah Berbasis Android ini bertujuan untuk memberikan kemudahan kepada pengguna dalam mempelajari materi mengenai ibadah secara lengkap dan 
jelas. Untuk itu penulis memberikan saran dalam upaya meningkatkan kualitas dan mengembangkan aplikasi ini :

1 Aplikasi Mobile Tuntunan Ibadah Berbasis Android ini memiliki kapasitas ukuran memori yang besar, untuk itu diperlukan penambahan kemampuan untuk dapat memindahkan memori ke dalam memori eksternal gadget, agar memori aplikasi tidak menghabiskan memori internal gadget.

2 Aplikasi Mobile Tuntunan Ibadah Berbasis Android ini dapat dikembangkan dalam penambahan menu bacaan-bacaan dalam shalat.

3 Aplikasi Mobile Tuntunan Ibadah Berbasis Android ini perlu dilakukan pengembangan dalam notifikasi alarm pengingat shalat fardhu, agar notifikasi alarm pengingat shalat fardhu dapat berisi notifikasi pengingat waktu shalat berdasarkan waktu shalat fardhu yang sedang berjalan diwaktu tersebut.

4 Aplikasi Mobile Tuntunan Ibadah Berbasis Android ini didalam melakukan setting alarm pengingat shalat fardhu masih dilakukan secara manual, sehingga perlu pengembangan dengan cara setting alarm otomatis yang memanfaatkan GPS pada gadget.

\section{DAFTAR PUSTAKA}

Amiral,M, 2010, AplikasiPengingatShalatdan Arah Kiblat menggunakan Global Positioning Sistem (GPS) berbasis Android 1.6, Program Studi Teknik Informatika, STMIK GI MDP.

Mulyadi, ST, 2010, Membuat Aplikasi Untuk Android, Multimedia Center publishing, Yogyakarta

Pressman, R., 2002, Rekayasa Perangkat Lunak Pendekatan Praktisi, Andi Offset, Yogyakarta.

Pinandita, T dan Mulyono, 2010, Aplikasi Handphone Pengingat Waktu Sholat Menggunakan Java2 Micro Edition, Fakultas Teknik, Universitas Muhammadiyah Purwokerto.

Saktiawan, D., 2008, SistemInformasi Berbasis Multimedia Tentang Tata Cara Ibadah Sholat Menurut Sunnah Nabi Menggunakan Macromedia Flash, Jurusan Teknik Elektro, Fakultas Teknik, Universitas Muhammadiyah Surakarta.

Sholiha, F \& Fauzi, K.M., 2009, Panduan Ibadah Haji dan Umroh Berbasis Ponsel, Program Studi Teknik Informatika, STMIK GI MDP. 